\title{
The role of education on Cancer amenable mortality among non-Hispanic blacks \& non-Hispanic whites in the United States (1989-2018)
}

Alberto Barcelo ${ }^{1,2^{*}}$, Linda Duffett-Leger ${ }^{3}$, Maria Pastor-Valero ${ }^{4,5}$, Juliana Pereira ${ }^{1}$, Fernando A. B. Colugnati ${ }^{1}$ and Edward Trapido ${ }^{6}$

\begin{abstract}
Background: Cancer mortality in the U.S. has fallen in recent decades; however, individuals with lower levels of education experienced a smaller decline than more highly educated individuals. This analysis aimed to measure the influence of education lower than a high school diploma, on cancer amenable mortality among Non-Hispanic Whites (NHW) and Non-Hispanic Blacks (NHB) in the U.S. from 1989 to 2018.

Methods: We analyzed data from 8.2 million death certificates of men and women who died from cancer between 1989 and 2018. We examined 5-year and calendar period intervals, as well as annual percent changes (APC). APC was adjusted for each combination of sex, educational level, and race categories (8 models) to separate the general trend from the effects of age.

Results: Our study demonstrated an increasing mortality gap between the least and the most educated NHW and NHB males and females who died from all cancers combined and for most other cancer types included in this study. The gap between the least and the most educated was broader among NHW males and females than among NHB males and females, respectively, for most malignancies.

Conclusions: In summary, we reported an increasing gap in the age-adjusted cancer mortality among the most and the least educated NHW and NHB between 25 and 74 years of age. We demonstrated that although NHB exhibited the greatest age-adjusted mortality rates for most cancer locations, the gap between the most and the least educated was shown for NHW.
\end{abstract}

\section{Introduction}

Low education is a strong predictor of high mortality in the United States (U.S.). The mortality gap between poorly and highly educated U.S. citizens has dramatically increased in recent years, particularly in specific subpopulations [1-3]. Mortality in the U.S. has declined more

\footnotetext{
* Correspondence: abarcelo@med.miami.edu

'Universidade Federal de Juiz de Fora, Juiz de Fora, Minas Gerais, Brazil ${ }^{2}$ Department of Public Health Science, Miller School of Medicine, University of Miami, P.O. Box 414037, Miami Beach, FL 33141, USA

Full list of author information is available at the end of the article
}

dramatically among the better educated than among less educated individuals [1-4].

Globally, cancer mortality increased from 7.7 million deaths in 2011 to 9.6 million deaths in 2017 [5, 6]. In the U.S., cancer mortality rates declined by $29 \%$, from 1991 to 2017 [7]. However, it did not reduce equally in all U.S. population segments [8]. A greater prevalence of cancer and lower screening rates has been reported among Non-Hispanic Blacks (NHB) and individuals with less than high school education, compared to Non-

(c) The Author(s). 2021 Open Access This article is licensed under a Creative Commons Attribution 4.0 International License, which permits use, sharing, adaptation, distribution and reproduction in any medium or format, as long as you give appropriate credit to the original author(s) and the source, provide a link to the Creative Commons licence, and indicate if changes were made. The images or other third party material in this article are included in the article's Creative Commons licence, unless indicated otherwise in a credit line to the material. If material is not included in the article's Creative Commons licence and your intended use is not permitted by statutory regulation or exceeds the permitted use, you will need to obtain permission directly from the copyright holder. To view a copy of this licence, visit http://creativecommons.org/licenses/by/4.0/ The Creative Commons Public Domain Dedication waiver (http://creativecommons.org/publicdomain/zero/1.0/) applies to the data made available in this article, unless otherwise stated in a credit line to the data. 
Hispanic Whites (NHW) and their better-educated peers, respectively [9-17].

NHW individuals born in 1980s with a lower than grade 12 education, presented cancer amenable mortality rates almost three times higher than their counterparts born in 1955 with a comparable level of education; however, during the same period, no significant differences were found among the most educated NHW individuals [8]. A greater prevalence of cancer and lower screening rates have been found among NHB and those with education lower than high school compared to NHW and their highly educated peers, respectively [9-11]. Potentially modifiable social determinants of health, such as access to health care services and socioeconomic status (SES), are associated with cancer mortality, screening, and treatment disparities among vulnerable populations in the U.S. [8, 12-17].

Compared to neighborhoods with favorable economic indicators, higher breast cancer mortality rates have been reported in places where people with unfavorable social determinants of health clustered (lower education, lower household income, and higher unemployment and proportion of uninsured population) [18-21]. The difference in breast cancer mortality between NHW and NHB women has been linked to education, family income, access to primary care physicians, and mammography in communities [22]. Complex interactions between race and different SES such as education and neighborhood SES (nSES) were identified as a factor in higher breast cancer mortality among various racial groups [23].

Implementation of the Affordable Care Act (ACA) has had a measurable impact on improving early diagnosis of cancer among low income populations [24, 25], particularly in some of the more preventable or treatable cancers such as cervical, breast, and colorectal cancer [26]. The aim of this analysis was to measure the influence of education lower than a high school diploma on cancer amenable mortality among NHW and NHB in the U.S. between 1989 and 2018.

\section{Methods}

\section{Study design and population}

We used a time-series design to analyze data from death certificates of 8.2 million men and women who died from cancer between 1989 and 2018. We used for our analysis, death certificate data from the U.S. National Center for Health Statistics (NCHS) and U.S. population estimates by age, gender, and ethnicity from the U.S. Census Bureau [27]. Information on race and education for a death certificate is reported by funeral directors, family members or taken from medical records (1989 to 2018) [28].

\section{Variables and data collection}

We selected mortality data due to specific cancer types, potentially amenable to appropriate health care, based on a modified version of the list published by Nolte et al. [29], as shown in Table 1.

Data on attained education and ethnicity were extracted from the death certificate databases. Counts of deaths due to colon, lung, breast, the body of the uterus, cervical, testis, prostate, Hodgkin's disease, leukemia as well other cancers, were used to calculate age-adjusted mortality rates from 1989 to 2018 , by year, sex, attained education (less than grade 12 or grade 12 and more) among NHW and NHB. We dichotomized the education variable into two groups of less than 12 years of education and 12 years or more of schooling, consistent with previous researchers [30,31]. This approach was taken since the highest mortality rates were reported among those with less than 12 years of schooling [32, 33], suggesting that not completing a high school education was a critical threshold for the risk of mortality in the U.S. Furthermore, attaining a high school diploma is an important step in decreasing yearly mortality rates among adults in the U.S. [34]. Dichotomizing the education variable facilitated a simple presentation of data [30-33, 35].

Individuals with less than 25 or more than 74 years of age and those with missing or unknown education, or races other than NHW or NHB, were excluded.

Overall, only $5.9 \%$ of available records of cancer deaths among NHW and NHB were excluded from the analysis because the level of education was classified as unknown. From the 16.7 million overall cancer deaths in the U.S. (1989-2018), only $0.9 \%$, the variable race was classified as unknown. We included 8.2 million deaths from a pool of 8.7 death certificates for NHW and NHB, who died from cancer between 1989 and 2018.

\section{Statistical analysis}

Age-and-sex standardized rates were calculated using the 2000 U.S. census population as a standard (https:// seer.cancer.gov/stdpopulations/stdpop.19ages.html). All analyses were restricted to individuals aged 25 to 74 years who died from cancers. We added deaths from prostate cancer to Nolte's list since this was the only major cause of cancer absent from their list [36].

We examined 5-year and calendar period intervals and annual percent changes (APC) adjusted for each combination of sex, educational level, and race categories to separate the general trend from the effects of age. Data analysis was conducted using the Joinpoint Regression Program (https://surveillance.cancer.gov/joinpoint/) as well as SPSS-26 and Stata-14 [37-39]. 
Table 1 Causes of death considered amenable to health care

\begin{tabular}{|c|c|c|c|c|}
\hline \multirow[t]{2}{*}{ Cause of death } & \multirow[t]{2}{*}{ Age } & \multicolumn{2}{|c|}{ International Classification of Disease } & \multirow[b]{2}{*}{ Comment } \\
\hline & & 9th revision & 10th revision & \\
\hline Malignant neoplasm of colon and rectum & $0-74$ & $153-4$ & $\mathrm{C} 18-21$ & - \\
\hline Malignant melanoma and other neoplasm of skin & $0-74$ & 173 & $\mathrm{C} 43-\mathrm{C} 44$ & - \\
\hline Malignant neoplasm of the breast & $0-74$ & 174 & $\mathrm{C} 50$ & Females only \\
\hline Malignant of the cervix uteri & $0-74$ & 180 & C53 & Females only \\
\hline Malignant of the body of uterus & $0-74$ & 179-182 & C54-C55 & Females only \\
\hline Malignant neoplasm of the testis & $0-74$ & 186 & C62 & Males only \\
\hline Malignant neoplasm of the prostate & $0-74$ & 185 & C61 & Males only \\
\hline Malignant neoplasm of the trachea, bronchus, and lung & $0-74$ & 162 & C33-C34 & - \\
\hline Hodgkin's disease & $0-74$ & 201 & C81 & - \\
\hline Leukemia & $0-74$ & $204-8$ & C91-C05 & - \\
\hline
\end{tabular}

\section{Results}

All amenable age-adjusted cancer mortality rates, between 1989 and 2018, increased in both sexes and races with education less than 12 years, while they decreased among those with 12 or more years of education (Fig. 1 A-B).

Age-adjusted amenable colon and rectum cancer mortality rates were lower among the most educated than among their least educated peers for both races and sexes (Fig. 1, C-D). Age-adjusted mortality rates for colon and rectum cancer for both sexes and races increased among the least educated while decreasing among the most educated. These trends were statistically significant (Table 2).

Age-adjusted skin cancer mortality rates (Fig. 2, A-B) were two to three times higher among NHW than their NHB peers. NHW men and women with lower levels of education presented lower mortality rates than their higher-educated peers between 1989 and 1998; however, trends for both NHW genders reversed in 1999-2018, showing consistently higher age-adjusted mortality rates among the less educated compared to the most educated.

Age-adjusted mortality due to lung and trachea cancer was three times higher among the less educated compared their most educated peers (Fig. 2, C-D). The APC analysis indicated statistically significant decreasing trends for NHW and NHB males and NHB women with 12 or more years of education (Table 2).

Age-adjusted amenable mortality rates for Hodgkin's disease and leukemia were the lowest for NHW males and females among the most educated, and they were comparably low for NHB of the same gender and education (Fig. 3, A-B, C-D). The least educated NHB men and women presented the highest age-adjusted mortality rates for Hodgkin's disease during the study period.

Age-adjusted cancer of the testis mortality rates (Fig. 4, A) was the highest among the less educated NHW and
NHB than the most educated peers. NHB men had ageadjusted cancer of the testis rates between $50 \%$ and $66 \%$ lower than NHW males. The age-adjusted mortality rate for prostate cancer (Fig. 4, B) was more than double among NHB men than NHW men.

Breast cancer mortality rates (Fig. 5, A) were the lowest among the most educated NHW, beginning 2000 when there was an increasing trend for the least educated NHW and NHB, respectively. The highest mortality rates during the study period were observed among the most educated NHB; however, there was a significant decreasing trend (APC - 1.4, $p<0.01$ ) among NHB women with an education of 12 years or higher (Table 2).

Age-adjusted mortality rates for cancer of the cervix (Fig. 5, B) were two to three times higher among the least educated than their most educated peers of both races, the gap was the biggest among NHW. The APC analysis indicated a statistically significant increasing trend among the least educated NHW (Table 2).

The age-adjusted mortality rate for the body of the uterus (Fig. 5 C) increased among females of both races and education levels; however, NHB with an education of 12 years and higher had higher mortality rates than all other groups. All four increasing trends were statistically significant (Table 2).

All other cancer age-adjusted mortality rates increased (Fig. 6 A-B) among the less educated and decreased among the most educated of both races and genders. APC indicated a statistically significant increasing trend among the less educated NHW men and women (Table 2).

\section{Discussion}

Our study demonstrated an increased mortality gap between the least and the most educated who died from most types of cancers. The gap between the least and most educated was broader for most malignancies among NHW than among NHB, respectively, suggesting delayed death from some of the most frequent cancers 


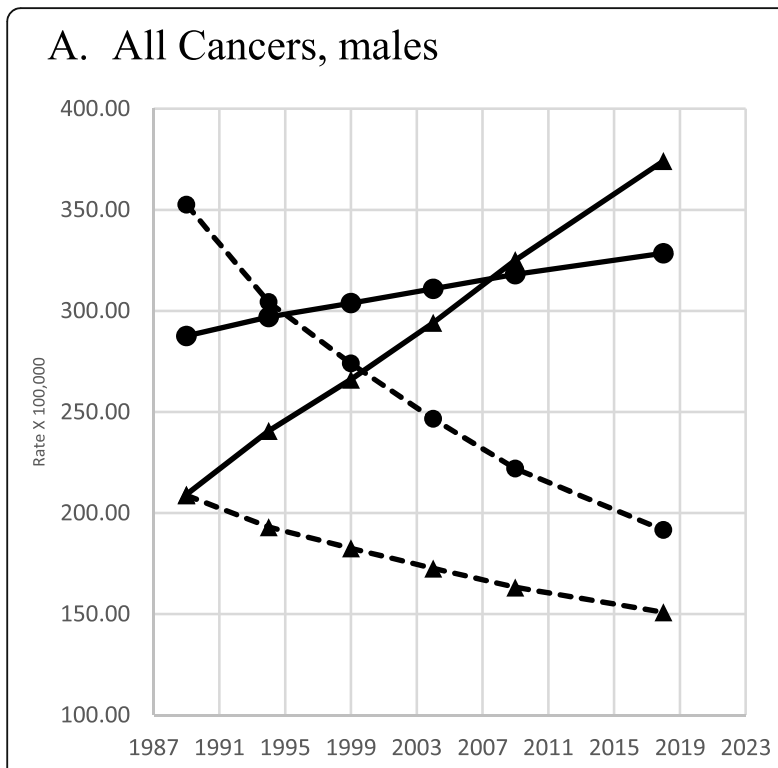

\section{Colon, males}

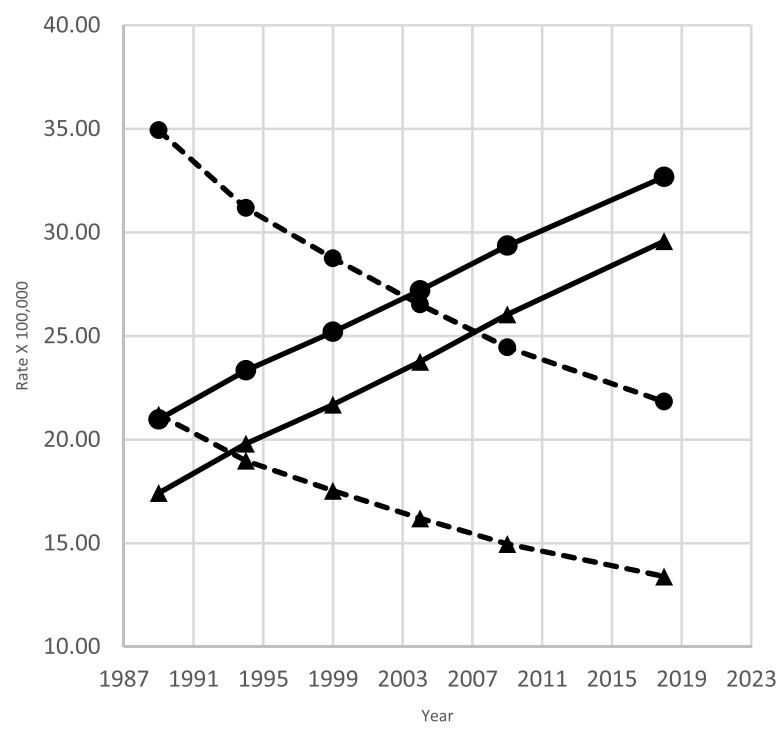

\section{B. All Cancers, females}

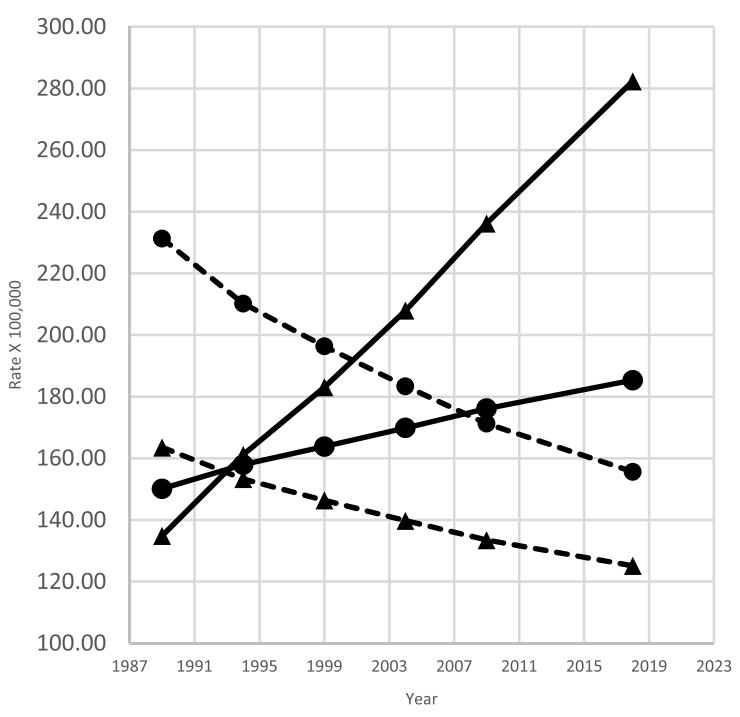

D. Colon, females

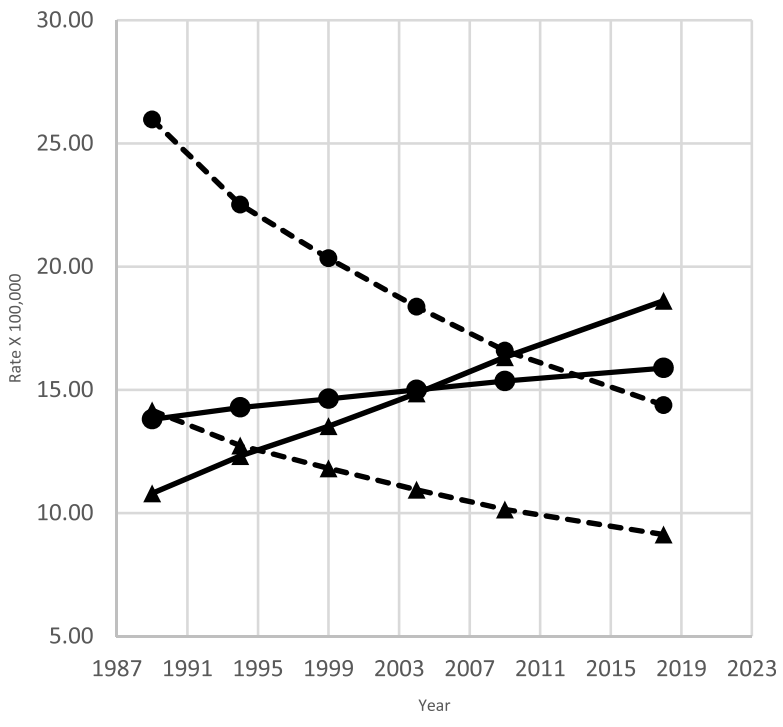

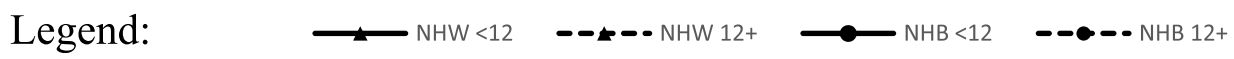

Fig. 1 Adjusted amenable mortality rate $(X 100,000)$ due all cancer and cancer of colon and rectum, with Joinpoint Regression (modeled line of trends), among NHW \& NHB by gender, period and education level. United States, 1989-2018. < 12: less than 12 years of education; $12+$ : 12 years of education or more. NHW: Non-Hispanic Whites; NHB: Non-Hispanic Blacks

among individuals in the U.S. with grade 12 or higher education [40].

Among the limitation of our study was the lack of additional variables, such as income or access to health insurance. Moreover, we relayed on the level of education reported on death certificates, which are subject to reporter's recall bias. Besides that, there are controversial reports regarding the reliability of the level of education information provided by death certificates. Research has demonstrated that a proportion of cases who attended high school are reported as graduated, even though they did not achieve a diploma. That would overestimate the number of high school graduates in our sample, especially among NHB. But this bias, however, is unlikely to change our results $[41,42]$ since the difference we found appears to be consistent across time, race, and cancer 
Table 2 Average annual percentage change APC (and 95\%-Cl) in mortality by type of cancer among NHW and NHB, by gender and education level. United States, 1989-2018

\begin{tabular}{|c|c|c|c|c|c|c|c|c|c|c|c|}
\hline & & & & Level of & cation & & & & & & \\
\hline & & & $<12 \mathrm{Ye}$ & & & & & $12+Y e$ & & & \\
\hline & Race & APC & $95 \%-\mathrm{Cl}$ & & & & APC & $95 \%-\mathrm{Cl}$ & & & \\
\hline & & & Lower & Upper & $\mathrm{t}$ & $p$ & & Lower & $\overline{\text { Upper }}$ & $\mathbf{t}$ & $p$ \\
\hline & & Males & & & & & & & & & \\
\hline All cancers & NHW & 2.0 & 1.0 & 3.1 & 5.6 & 0.0 & -1.1 & -1.7 & -0.5 & -5.2 & 0.0 \\
\hline & NHB & 0.5 & -0.9 & 1.9 & 0.9 & 0.4 & -2.1 & -3.0 & -1.2 & -6.5 & 0.0 \\
\hline Colon \& rectum & NHW & 1.8 & 1.0 & 2.7 & 6.1 & 0.0 & -1.6 & -2.2 & -0.9 & -6.7 & 0.0 \\
\hline & NHB & 1.5 & -0.2 & 3.3 & 2.5 & 0.1 & -1.6 & -2.6 & -0.6 & -4.4 & 0.0 \\
\hline Skin & NHW & 2.6 & 1.2 & 4.0 & 5.3 & 0.0 & -0.4 & -1.2 & 0.4 & -1.4 & 0.2 \\
\hline & $\mathrm{NHB}$ & -0.6 & -1.5 & 0.4 & -1.7 & 0.2 & -2.4 & -2.9 & -1.9 & -13.1 & 0.0 \\
\hline Trachea, bronchus \& lung & NHW & 1.5 & 0.3 & 2.8 & 3.6 & 0.0 & -2.1 & -3.1 & -1.1 & -5.7 & 0.0 \\
\hline & NHB & -0.2 & -1.8 & 1.5 & -0.3 & 0.8 & -3.2 & -4.4 & -2.0 & -7.2 & 0.0 \\
\hline Hodgkin's disease & NHW & 1.1 & -1.0 & 3.2 & 1.4 & 0.2 & -2.8 & -3.3 & -2.3 & -16.9 & 0.0 \\
\hline & NHB & 0.3 & -1.7 & 2.3 & 0.4 & 0.7 & -3.0 & -4.1 & -1.8 & -7.1 & 0.0 \\
\hline Leukemia & NHW & $1.8^{*}$ & 0.4 & 3.1 & 3.7 & 0.0 & -1.0 & -2.0 & -0.1 & -3.1 & 0.0 \\
\hline & NHB & 0.7 & -0.9 & 2.3 & 1.2 & 0.3 & -1.6 & -2.5 & -0.7 & -5.1 & 0.0 \\
\hline Testis & NHW & 4.3 & 1.3 & 7.4 & 4.0 & 0.0 & 0.3 & -0.5 & 1.0 & 1.0 & 0.4 \\
\hline & NHB & 1.4 & -3.4 & 6.4 & 0.8 & 0.5 & 0.1 & -2.6 & 2.8 & 0.1 & 1.0 \\
\hline Prostate & NHW & -0.3 & -0.4 & -0.2 & -7.3 & 0.0 & -2.5 & -3.3 & -1.6 & -8.1 & 0.0 \\
\hline & NHB & -0.3 & -2.2 & 1.6 & -0.5 & 0.6 & -2.7 & -3.8 & -1.6 & -6.7 & 0.0 \\
\hline Other types & NHW & 2.8 & 1.8 & 3.8 & 7.8 & 0.0 & -0.2 & -0.7 & 0.3 & -1.2 & 0.3 \\
\hline & NHB & 0.9 & -0.2 & 2.0 & 2.4 & 0.1 & -1.3 & -2.0 & -0.6 & -5.1 & 0.0 \\
\hline & & Female & & & & & & & & & \\
\hline All cancers & NHW & 2.6 & 1.3 & 3.9 & 5.4 & 0.0 & -0.9 & -1.6 & -0.3 & -3.9 & 0.0 \\
\hline & NHB & 0.7 & -0.2 & 1.7 & 2.1 & 0.1 & -1.4 & -2.1 & -0.6 & -5.2 & 0.0 \\
\hline Colon \& rectum & NHW & 1.9 & 0.9 & 2.9 & 5.4 & 0.0 & -1.5 & -2.2 & -0.9 & -6.4 & 0.0 \\
\hline & NHB & 0.5 & -0.6 & 1.6 & 1.2 & 0.3 & -2.0 & -2.9 & -1.1 & -6.0 & 0.0 \\
\hline Skin & NHW & 2.6 & 1.0 & 4.3 & 4.5 & 0.0 & -0.4 & -1.3 & 0.4 & -1.4 & 0.2 \\
\hline & NHB & 1.1 & -0.3 & 2.5 & 2.1 & 0.1 & -2.1 & -3.0 & -1.3 & -6.9 & 0.0 \\
\hline Trachea, bronchus \& lung & NHW & 3.4 & 1.6 & 5.3 & 5.2 & 0.0 & -0.9 & -2.2 & 0.3 & -2.1 & 0.1 \\
\hline & NHB & 1.1 & -0.6 & 2.8 & 1.8 & 0.2 & -1.9 & -3.1 & -0.7 & -4.3 & 0.0 \\
\hline Hodgkin's Disease & NHW & 2.2 & 0.9 & 3.6 & 4.6 & 0.0 & -2.7 & -4.4 & -1.0 & -4.5 & 0.0 \\
\hline & NHB & 0.8 & -1.0 & 2.7 & 1.2 & 0.3 & -2.5 & -3.8 & -1.3 & -5.5 & 0.0 \\
\hline Leukemia & NHW & 1.8 & 0.5 & 3.1 & 3.8 & 0.0 & -1.1 & -1.9 & -0.2 & -3.4 & 0.0 \\
\hline & NHB & 0.3 & -0.6 & 1.3 & 1.0 & 0.4 & -1.4 & -2.0 & -0.7 & -5.9 & 0.0 \\
\hline Breast & NHW & 1.0 & -0.3 & 2.2 & 2.2 & 0.1 & -1.8 & -2.2 & -1.3 & -11.3 & 0.0 \\
\hline & NHB & 0.5 & -0.5 & 1.4 & 1.4 & 0.2 & -1.4 & -2.1 & -0.7 & -5.3 & 0.0 \\
\hline Cervix uteri & NHW & 3.1 & 2.0 & 4.2 & 7.9 & 0.0 & -0.4 & -0.9 & 0.2 & -1.9 & 0.1 \\
\hline & NHB & -0.4 & -1.3 & 0.4 & -1.4 & 0.2 & -2.2 & -3.0 & -1.4 & -7.4 & 0.0 \\
\hline Body of uterus & NHW & 3.1 & 2.3 & 4.0 & 10.3 & 0.0 & 1.3 & 1.0 & 1.5 & 15.9 & 0.0 \\
\hline & $\mathrm{NHB}$ & 2.3 & 1.8 & 2.7 & 14.7 & 0.0 & 1.5 & 1.1 & 1.9 & 10.1 & 0.0 \\
\hline Other types & NHW & 2.4 & 1.2 & 3.7 & 5.7 & 0.0 & -0.5 & -1.2 & 0.1 & -2.3 & 0.1 \\
\hline & $\mathrm{NHB}$ & 0.7 & -0.1 & 1.6 & 2.4 & 0.1 & -1.1 & -1.8 & -0.4 & -4.5 & 0.0 \\
\hline
\end{tabular}

$<12$ less than 12 years of education; $12+12$ years of education or more NHW Non-Hispanic Whites; NHB Non-Hispanic Blacks 


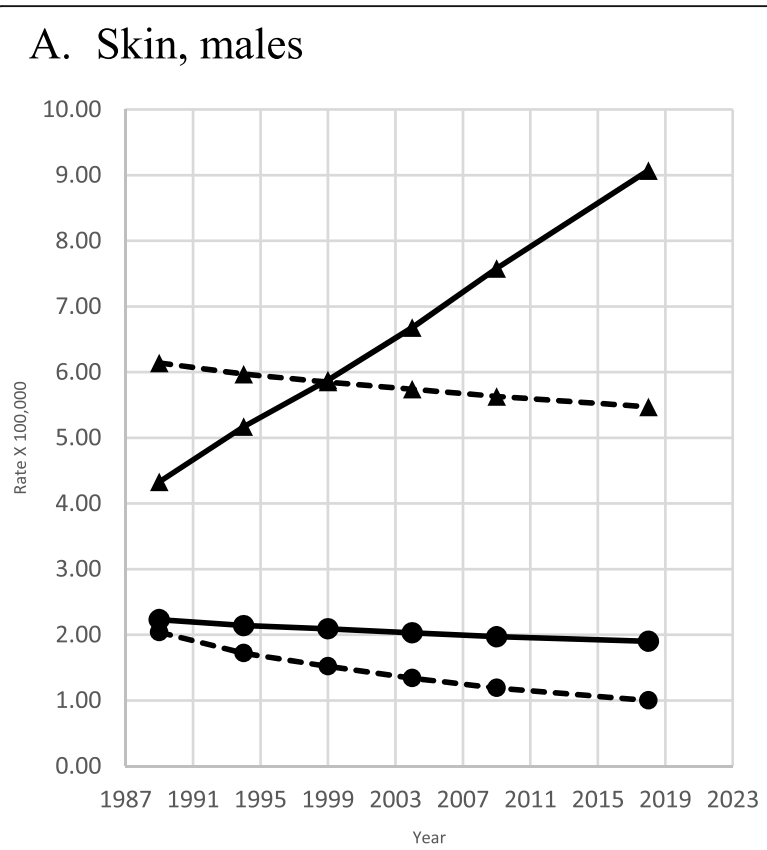

C. Lung, males

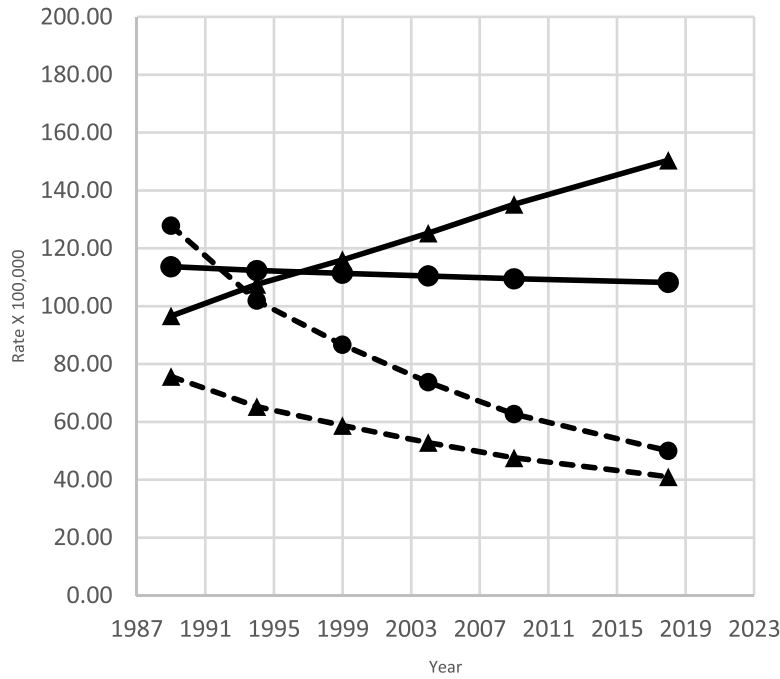

Legend: $\quad \longrightarrow$ NHW $<12 \quad---\boldsymbol{- -}$ NHW $12+$
B. Skin, females

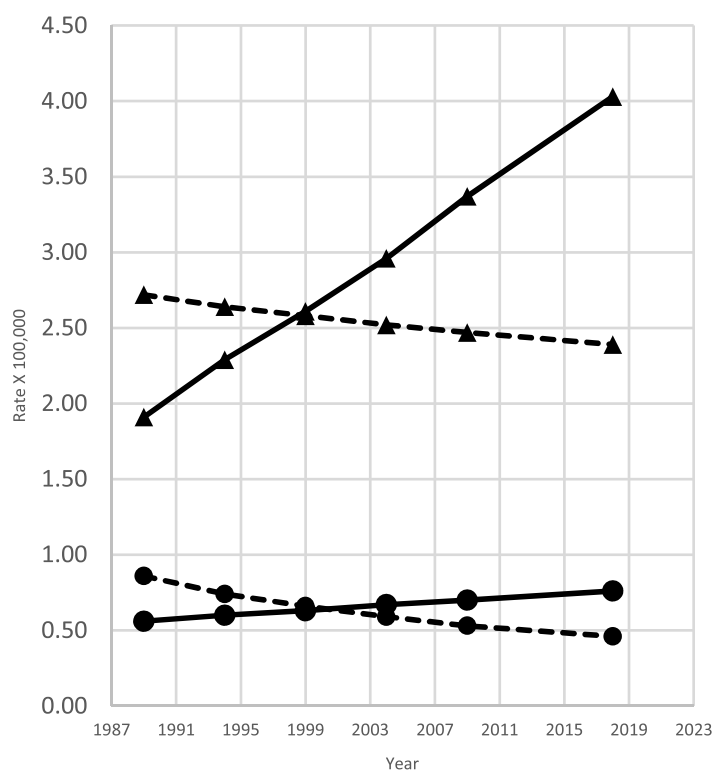

D. Lung, females

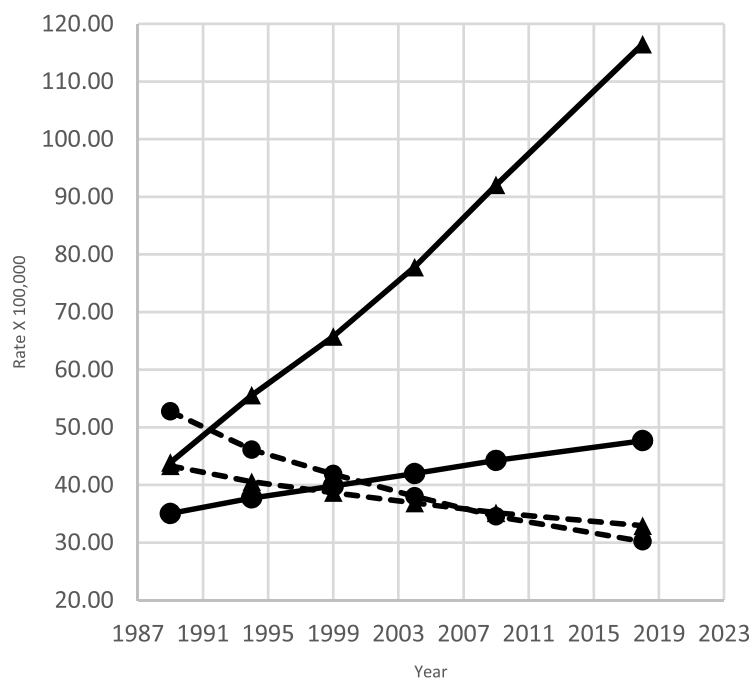

$\longrightarrow \mathrm{NHB}<12 \quad--\bullet--\mathrm{NHB} 12+$

Fig. 2 Adjusted amenable mortality rate $(X 100,000)$ due to cancer of the skin and cancer of the trachea, bronchus, and lung with Joinpoint Regression (modeled line of trends) among NHW \& NHB by gender, period and education level. United States, 1989-2018. < 12: less than 12 years of education; 12+: 12 years of education or more. NHW: Non-Hispanic Whites; NHB: Non-Hispanic Blacks

type. Analyzing age-and-sex adjusted 5-year periods eliminated slight variations that might have occurred in a particular year, state, or race. While we cannot rule out a birth cohort influence, on many cancer type mortality rates, since recent research has demonstrated an increasing trend of cancer incidence among young adults in the US due to variation in risk factor frequency [43] the impact on our results are likely negligible.

The strength of using the level of education as an SES factor in health research lies in its lifetime stability and inclusiveness of measurement. Education is less likely to be influenced by adulthood health or 
A. Hodgkin disease, males

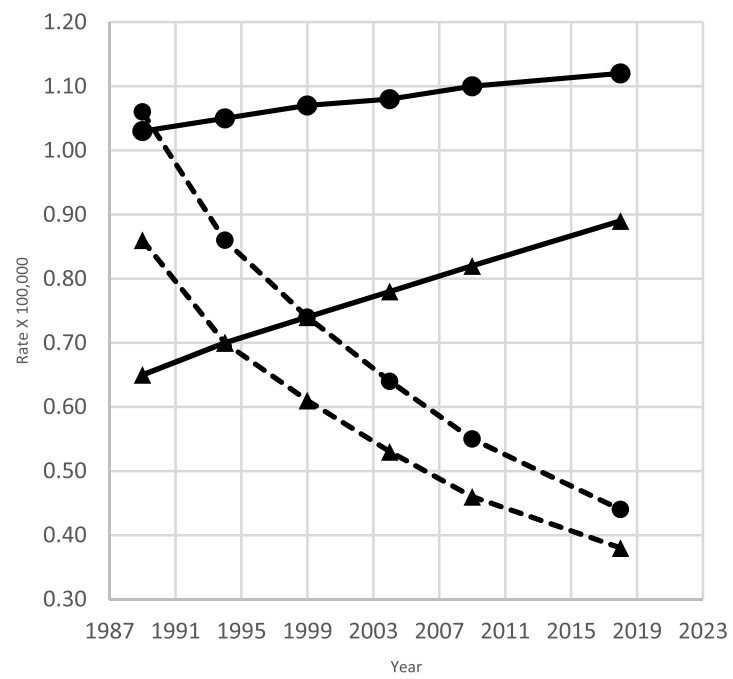

C. Leukemia, males

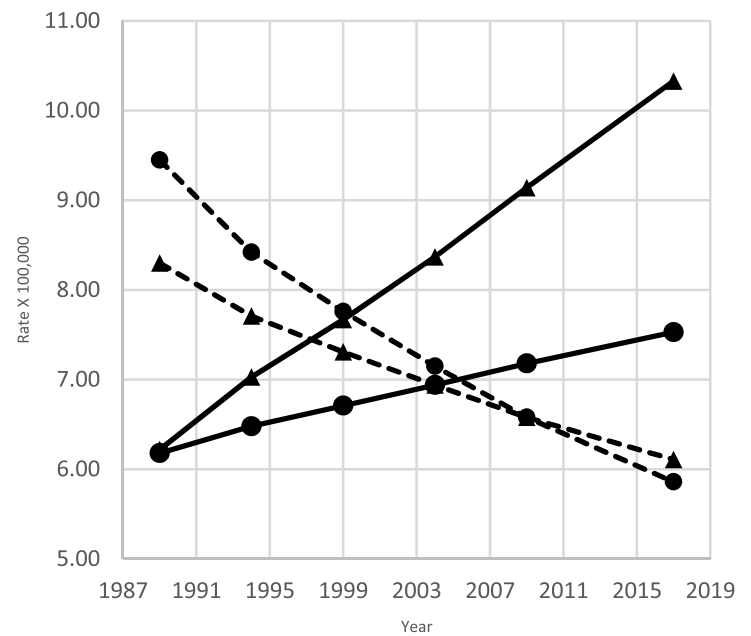

B. Hodgkin disease, females

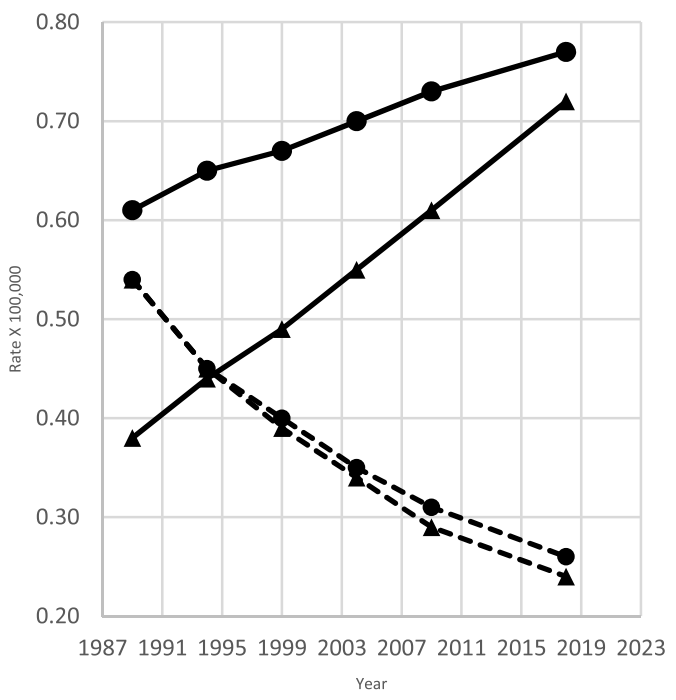

D. Leukemia, females

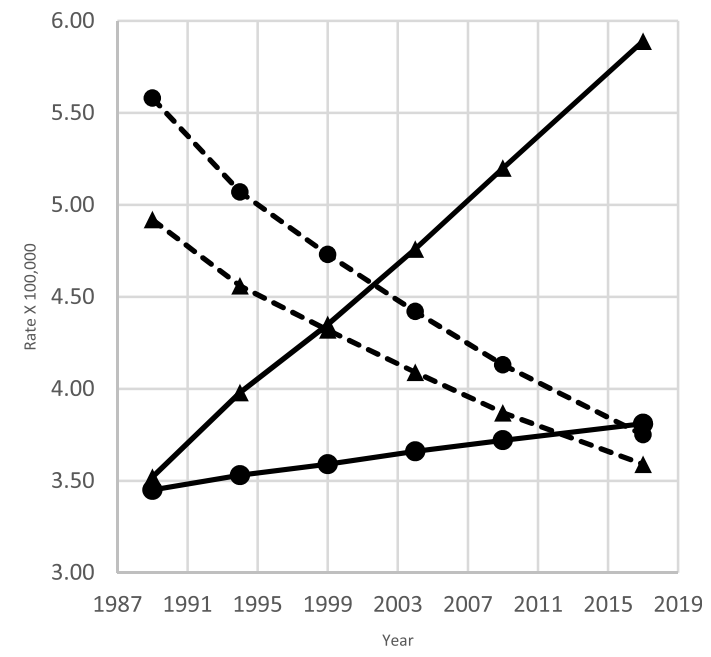

\section{Legend:}

$\longrightarrow$ NHW $<12 \quad$ - - $-\boldsymbol{-}$ NHW $12+$

$\longrightarrow$ NHB $<12 \quad--\bullet--N H B 12+$

Fig. 3 Adjusted amenable mortality rate (X100,000) due to Hodgkin's disease and leukemia, with Joinpoint Regression (modeled line of trends), among NHW \& NHB by gender, period and education level. United States, 1989-2018. < 12: less than 12 years of education; 12+: 12 years of education or more. NHW: Non-Hispanic Whites; NHB: Non-Hispanic Blacks

income. Higher education is considered a good predictor of improved lifestyles and behaviors, better jobs, housing, working conditions, and income [4, 4446]. Conversely, the effect of education might have different meanings and returns across the racial spectrum of the U.S. population. Having less than a 12th grade education is one of the greatest SES contributors to premature mortality when considering poverty, low social support, income, racial segregation, and health insurance [11, 30, 31, 47].
Implementing evidence-based programs focused on social factors such as education and environmental context to reduce cancer screening disparities between NHB and NHW is recommended [40, 48]. Although recent statistics suggest lower (or comparable) death rates among NHW and NHB due to certain cancers such as breast, prostate, cervix, colon and rectum [7], our data showed that this decrease was only apparent in some segments of the U.S. population, i.e., the most educated NHW. In particular, melanoma of the skin and cancer of 


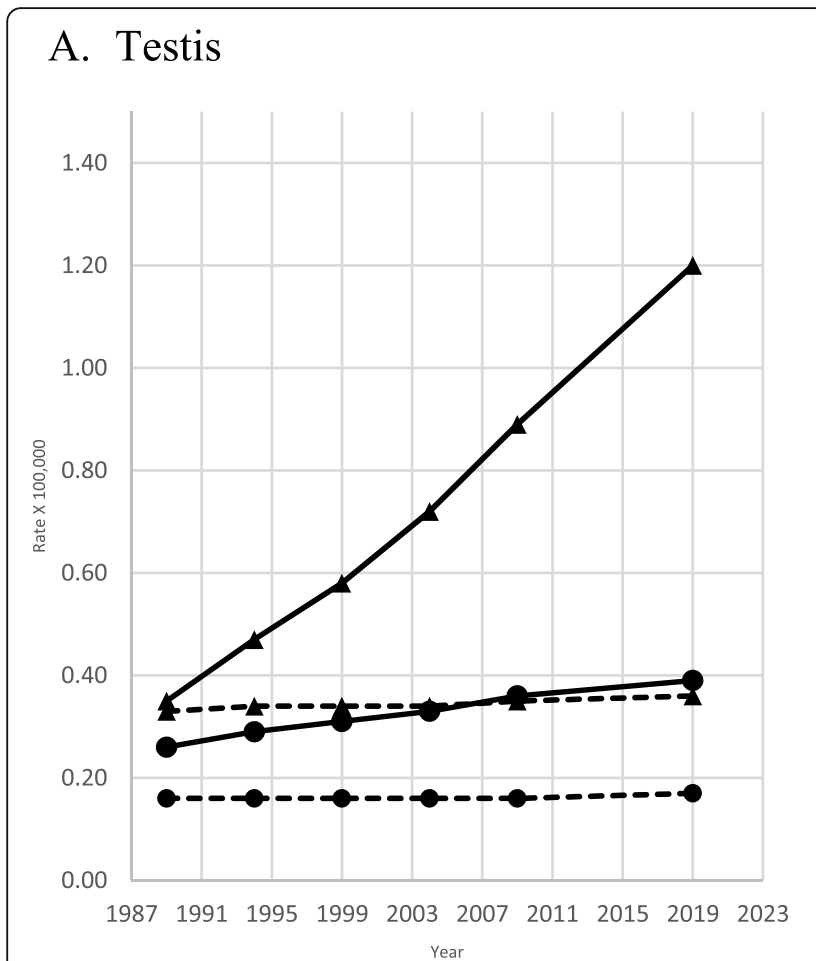

\section{Legend:}

Fig. 4 Adjusted amenable mortality rate $(X 100,000)$ due to cancer of the testis and prostate cancer with Joinpoint Regression (modeled line of trends), among NHW \& NHB males by period and education level. United States, 1989-2018. < 12: less than 12 years of education; $12+$ : 12 years of education or more. NHW: Non-Hispanic Whites; NHB: Non-Hispanic Blacks

\section{B. Prostate}

Year

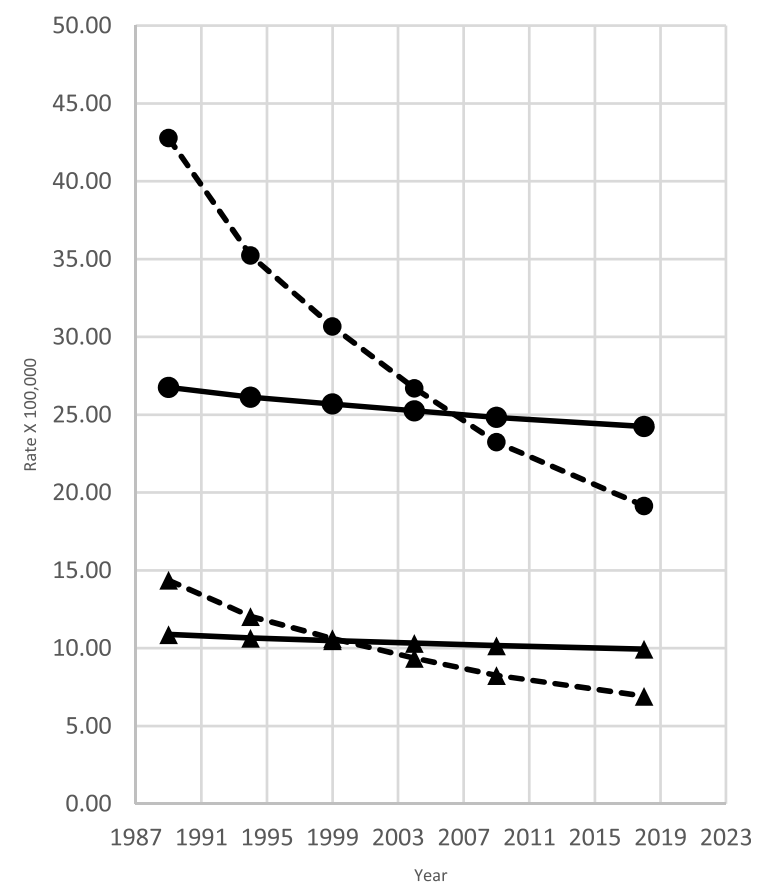

the testis has been reported to be more frequent among NHW than among NHB [49].

Many risk factors have been identified as causing cancer mortality disparities among U.S. racial groups [50]. Lower SES was related to lower awareness for breast cancer symptoms and prevention $[17,51]$, resulting in more advanced stage cancer presentations at diagnosis than disparities in treatment or access to health insurance $[16,17,22,52-55]$.

Age-adjusted cancer mortality of three types of cancers (leukemia, breast, and body of the uterus) was found to be higher among the most educated NHB than their least educated peers. Age-adjusted mortality rates for the body of the uterus cancer showed a steady increase in all subpopulation groups. Although our data suggest the influence of education (attaining 12 years or more) on mortality rates for most major cancers, this factor did not appear to have the same detrimental effect on cancer deaths from leukemia, breast, and body of the uterus among NHB women. While access to oral contraceptive use [56] or hormone replacement therapy [57] may play a role in this issue, it is likely an interaction of other important risk factors. Incidence studies have demonstrated lower breast cancer incidence among NHB women than NHW women $[7,58]$. Additionally, breast cancer mortality rates have been reported to be more than 30\% higher among NHB than among NHW women [47]. It is also possible that we missed some of the known race specific breast cancer differences since we did not analyze the age-specific rate by race and education. For instance, the presentation of triple negative aggressive breast cancer among young age NHB women that appears later in life among NHW women $[59,60]$.

A lower proportion of women of color compared to NHW women reported having mammography during the previous 2 years [61]. Our data showed that breast cancer and cancer of the uterus age-adjusted mortality rates among the most educated NHB women, between the age of 25 and 44 years (data not shown), were slightly lower than their least educated peers. These findings indicate that the increase in breast and uterine cancer mortality among the most educated NHB may be the result of greater mortality among postmenopausal women (data not shown) compared to women before the age of 45 years of age, due to greater likelihood of hormone replacement therapy use among members of this group. A decreased use of hormone replacement therapy has been related to a lower incidence of breast 


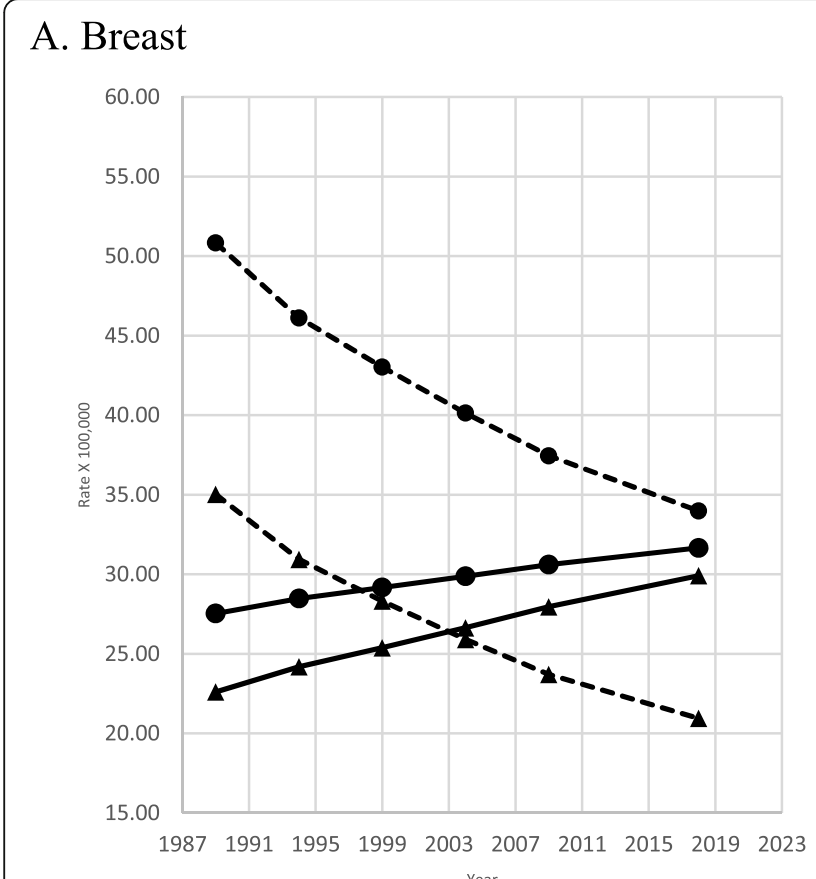

B. Cervix

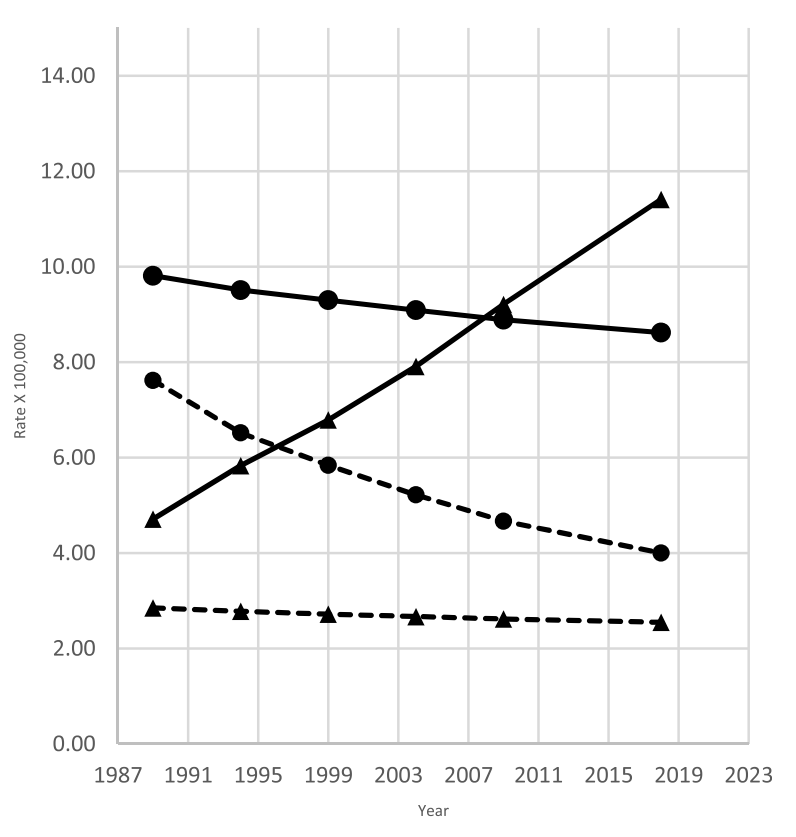

\section{Body of uterus}

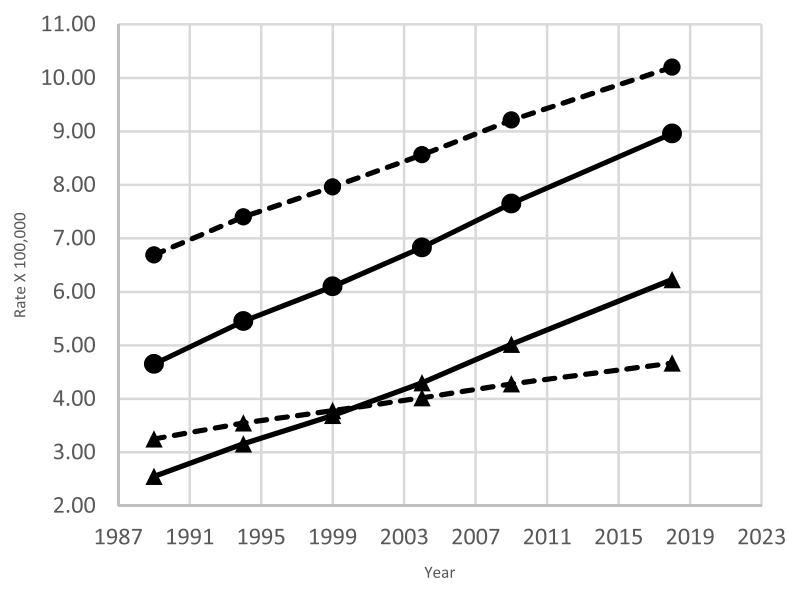

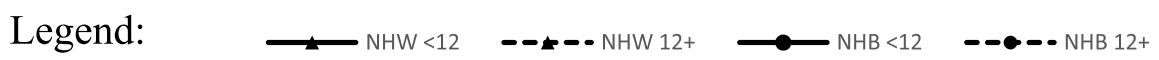

Fig. 5 Adjusted amenable mortality rate $(X 100,000)$ due to breast, cervix uteri, and body of uterus cancer, with Joinpoint Regression (modeled line of trends), among NHW \& NHB females by period and education level. United States, 1989-2018. < 12: less than 12 years of education; $12+$ : 12 years of education or more. NHW: Non-Hispanic Whites; NHB: Non-Hispanic Blacks

cancer among NHW women [62]. Other factors that may be involved in the observed differences are limited availability of community mammography facilities [22], increased delays in cancer treatment among women of color, and lack of health insurance [63]. NHB women living in low SES areas showed poorer breast cancer outcomes than NHW women who were recipients of the same government-subsidized health services, even after adjusting by the level of education [64].
Research exploring the complex multi-factorial causes such as biological, social, health system factors, hormone replacement therapy, and contraceptive use may help explain our findings $[49,56,57,65-71]$.

The Global Burden of Disease (GDB) study showed that country cancer profiles depend on the combination of different exposures to risk factors and socioeconomic and health care access conditions [72]. The prevention of cancer mortality in underserved populations requires 


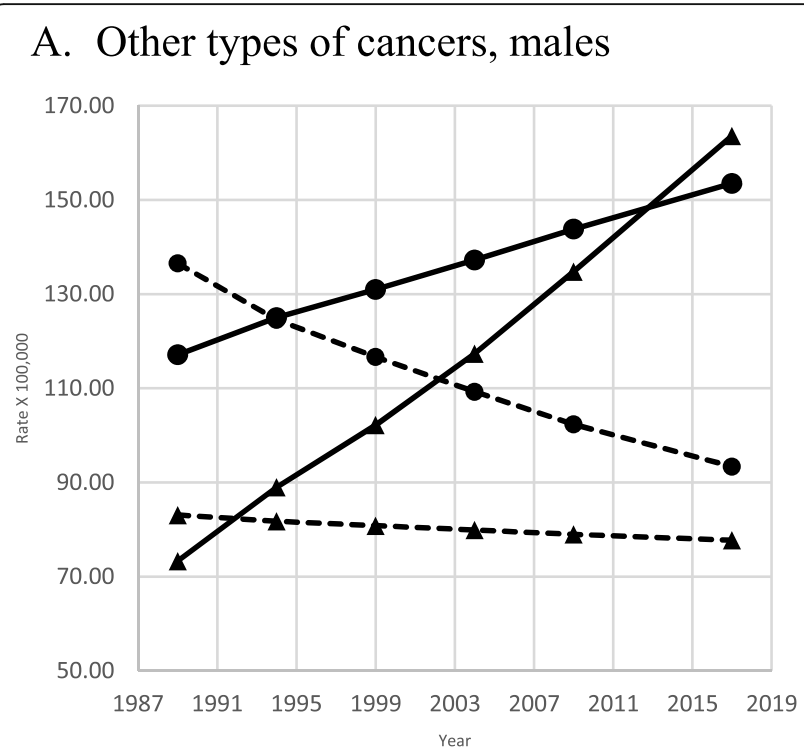

\section{B. Other types of cancers, females}

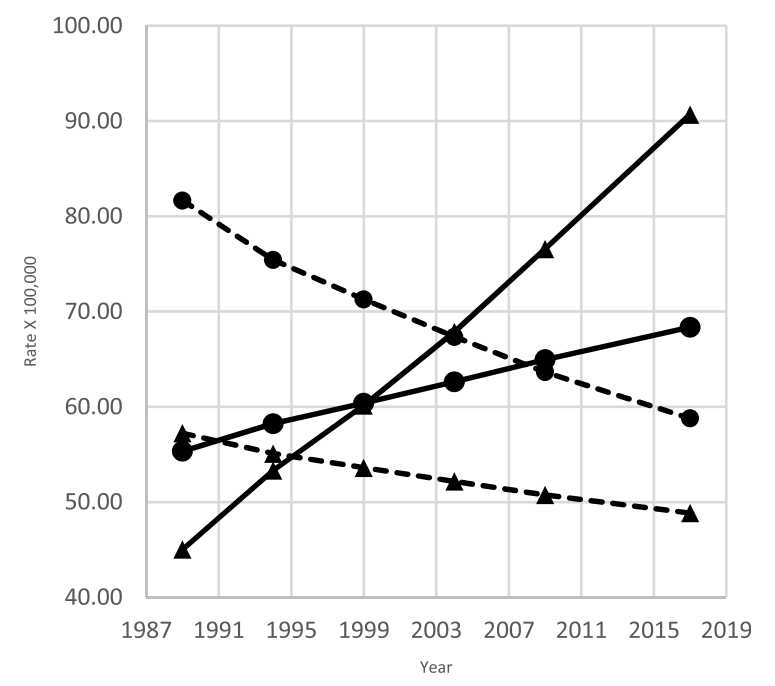

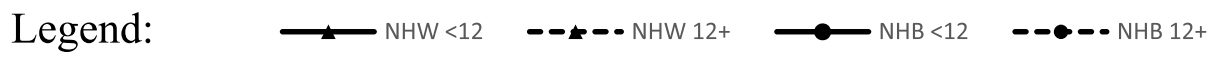

Fig. 6 Adjusted amenable mortality rate $(X 100,000)$ due to all other types of cancer, with Joinpoint Regression (modeled line of trends), among NHW \& NHB, by gender, period and education level. United States, 1989-2018. < 12: less than 12 years of education; 12+: 12 years of education or more. NHW: Non-Hispanic Whites; NHB: Non-Hispanic Blacks

increasing healthcare coverage and outreach programs to overcome barriers related to stigma, clinician implicit bias, and nihilism [73]. Furthermore, this disparity demonstrates a need for culturally appropriate cancer prevention interventions tailored to the unique demands of the most vulnerable groups in the U.S. population for success [40].

In summary, we reported an increasing gap in the ageadjusted cancer mortality among the most and the least educated NHW and NHB between 25 and 74 years of age. These deaths are amenable to access to quality health care improvement. We also found that the most educated NHW had lower mortality rates for most malignancies than the less-educated NHW and their most educated and least educated NHB peers.

Although national statistics reported that the overall declines in cancer death rates in the U.S. were the result of significant decreases in four leading cancers (lung, colorectal, breast, and prostate cancers) [7], our data showed an increasing trend of cancer mortality among the least educated NHW and NHB for the same four (and others) types of cancers. These findings suggest notable educational and racial disparities in the prevention of cancer incidence, treatment, and mortality among some segments of the U.S. population, which can probably be circumvented by increasing access to prevention, screening, and enhanced quality treatment of cancer among some sub-populations. We also demonstrated that although NHB exhibited the highest age- adjusted mortality rates for most cancer locations, the greatest gap between the most and the least educated was shown for NHW.

Decreasing educational and racial health disparities may improve access to screening, as well as preventive and quality care for a large segment of the population and further reduce premature cancer mortality in the U.S.

\section{Abbreviations}

The U.S.: United States of America; NCD: Non-communicable diseases; NHW: Non-hispanic whites; NHB: Non-hispanic whites; L.E.: Life expectancy; ACP: Annual percentage changes; 95\%-Cl: 95\% Confidence intervals; SES: Socioeconomic status; nSES: Neighborhood SES; GBD: Global burden of disease; ACA: Affordable care act

\section{Supplementary Information}

The online version contains supplementary material available at https://doi. org/10.1186/s12885-021-08633-7.

Additional file 1: Table S1. Adjusted amenable cancer mortality rates (X100,000) and 95\% Confidence Intervals (Cl) among NHW and NHB by gender and education level. United States, 1989-2018. Table S2. Adjusted amenable colon and rectum* mortality rates (X100,000) and 95\% Confidence Intervals (Cl) among NHW and NHB by gender and education level. United States, 1989-2018. Table S3. Adjusted amenable skin cancer* mortality rates (X100,000) and 95\% Confidence Intervals (Cl) among NHW and NHB by gender and education level. United States, 1989-2018. Table S4. Adjusted amenable lung and trachea cancer* mortality rates $(X 100,000)$ and $95 \%$ Confidence Intervals $(C I)$ among NHW and NHB men by education level. United States, 1989-2018. Table S5. Adjusted amenable Hodgkin's disease ${ }^{*}$ mortality rates $(X 100,000)$ and 95\% Confidence intervals (CI) among NHW and NHB by gender and education level. United States, 1989-2018. Table S6. Adjusted amenable 
leukemia* mortality rates (X100,000 and 95\% Confidence intervals (CI) among NHW and NHB (25-74 years of age) by gender and education level. United States, 1989-2018. Table S7. Adjusted amenable testis cancer* rates (X100,000 and 95\% Confidence intervals (Cl) among NHW and NHB men by education level. United States, 1989-2018. Table S8. Adjusted amenable prostate cancer* mortality rates (X100,000 and $95 \%$ Confidence intervals $(\mathrm{Cl})$ among NHW and NHB men by education level. United States, 1989-2018. Table S9. Adjusted amenable breast cancer* mortality rates $(\mathrm{X} 100,000)$ and $95 \%$ Confidence intervals $(\mathrm{Cl})$ among NHW and NHB by education level. United States, 1989-2018. Table S10. Adjusted amenable cervix cancer* mortality rates $(X 100,000)$ and $95 \%$ Confidence intervals $(\mathrm{Cl})$ among NHW and NHB by education level. United States, 1989-2018. Table S11. Adjusted amenable body of uterus cancer* mortality rates $(X 100,000)$ and $95 \%$ Confidence intervals (Cl) among NHW and NHB female by education level. United States, 19892018. Table S12. Adjusted amenable other type cancers* mortality rates (X100,000) and 95\% Confidence intervals (Cl) among NHW and NHB by gender and education level. United States, 1989-2018.

\section{Acknowledgments}

N/A

\section{Authors' contributions}

AB: Conceptualization, literature search data curation, data analysis, data interpretation and analysis, original drafting, review, editing, and discussion. MPV: Literature search, data analysis, interpretation, analysis, and discussion. A.B., MPV, LDL, FABC, J.P., E.T.: Data interpretation and discussion, manuscript writing, review and editing. All authors reviewed the manuscript. The authors thank the support of the Graduate Support Program (PROAP), and the Coordination for the Improvement of Higher Education Personnel (CAPES), from the University of Juiz de Fora. The author(s) read and approved the final manuscript.

\section{Funding}

No funding was received for the completion of this research and publication.

\section{Availability of data and materials}

The datasets generated and analyzed during the current study are available in this repository https://drive.google.com/drive/folders/1 HHjdOZOQIAKKwFmsUYt-OSdAh2C485QZ?usp=sharing in SPSS format.

\section{Declarations}

Ethics approval and consent to participate

Ethics institutional review board approval for this study was unnecessary since it was based on publicly available data.

All authors approved the final version of the manuscript.

\section{Consent for publication}

All authors have provided consent for publication.

\section{Competing interests}

All the authors declared that there was not any conflict or competing interest.

\footnotetext{
Author details

${ }^{1}$ Universidade Federal de Juiz de Fora, Juiz de Fora, Minas Gerais, Brazil. ${ }^{2}$ Department of Public Health Science, Miller School of Medicine, University of Miami, P.O. Box 414037, Miami Beach, FL 33141, USA. ${ }^{3}$ Faculty of Nursing, University of Calgary, Calgary, Canada. ${ }^{4}$ Departamento de Salud Pública, História de la Ciencia y Ginecología, Facultad de Medicina, Universidad Miguel Hernández de Elche, Elche, Spain. ${ }^{5}$ Centro de Investigación Biomédica en Red de Epidemiología y Salud Publica (Ciberesp), Madrid, Spain. ${ }^{6}$ Stanley S. Scott Cancer Center, LSU School of Public Health, New Orleans, USA.
}

Received: 3 March 2021 Accepted: 26 July 2021

Published online: 07 September 2021

\section{References}

1. Olshansky SJ, Antonucci T, Berkman L, Binstock RH, Boersch-Supan A, Cacioppo JT, et al. Differences in life expectancy due to race and educational differences are widening, and many may not catch up. Health Affairs (Project Hope). 2012;31(8):1803-13. https://doi.org/10.1377/hlthaff.2 011.0746 .

2. Krueger PM, Tran MK, Hummer RA, Chang WW. Mortality attributable to low levels of education in the United States. PLoS One. 2015;10(7):e0131809. https://doi.org/10.1371/journal.pone.0131809.

3. Masters RK, Link BG, Phelan JC. Trends in education gradients of 'preventable' mortality: a test of fundamental cause theory. Soc Sci Med. 2015;127:19-28. https://doi.org/10.1016/.jocscimed.2014.10.023.

4. Cutler DM, Lange F, Meara E, Richards-Shubik S, Ruhm CJ. Rising educational gradients in mortality: the role of behavioral risk factors. J Health Econ. 2011; 30(6):1174-87. https://doi.org/10.1016/j.jhealeco.2011.06.009.

5. Global Burden of Disease Cancer C, Fitzmaurice C, Akinyemiju TF, Al Lami FH, Alam T, Alizadeh-Navaei R, et al. Global, regional, and national cancer incidence, mortality, years of life lost, years lived with disability, and disability-adjusted life-years for 29 cancer groups, 1990 to 2016: a systematic analysis for the global burden of disease study. JAMA Oncol. 2018;4(11): 1553-68.

6. McGuire S. World cancer report 2014. Geneva, Switzerland: world health organization, international agency for research on cancer, WHO press, 2015. Adv Nutr. 2016;7(2):418-9.

7. Siegel RL, Miller KD, Jemal A. Cancer statistics, 2020. CA Cancer J Clin. 2020; 70(1):7-30. https://doi.org/10.3322/caac.21590

8. Barcelo A, Colugnati F, Pastor-Valero M. The role of education and ethnicity on amenable mortality due to five leading non-communicable diseases among Blacks and Whites in the United States, 1990-2015. J Glob Health Rep. 2020;4:e2020050. https://doi.org/10.29392/001c.13068.

9. Rawl SM, Dickinson $S$, Lee JL, Roberts JL, Teal E, Baker LB, et al. Racial and socioeconomic disparities in Cancer-related knowledge, beliefs, and behaviors in Indiana. Cancer Epidemiol Biomark Prev. 2019;28(3):462-70. https://doi.org/10.1158/1055-9965.EPI-18-0795.

10. Tsai MH, Xirasagar S, de Groen PC. Persisting racial disparities in colonoscopy screening of persons with a family history of colorectal Cancer. J Racial Ethn Health Disparities. 2018;5(4):737-46. https://doi.org/10.1007/s4 0615-017-0418-1.

11. Sauer AG, Siegel RL, Jemal A, Fedewa SA. Current prevalence of major cancer risk factors and screening test use in the United States: disparities by education and race/ethnicity. Cancer Epidemiol Biomarkers Prev. 2019;28(4): 629-42. https://doi.org/10.1158/1055-9965.EPI-18-1169.

12. Wasif N, Etzioni D, Habermann EB, Mathur A, Pockaj BA, Gray RJ, et al. Racial and socioeconomic differences in the use of high-volume commission on Cancer-accredited hospitals for Cancer surgery in the United States. Ann Surg Oncol. 2018;25(5):1116-25. https://doi.org/10.1245/s10434-018-6374-0.

13. Dreyer MS, Nattinger AB, McGinley EL, Pezzin LE. Socioeconomic status and breast cancer treatment. Breast Cancer Res Treat. 2018;167(1):1-8. https:// doi.org/10.1007/s10549-017-4490-3.

14. Vick AD, Hery DN, Markowiak SF, Brunicardi FC. Closing the disparity in pancreatic Cancer outcomes: a closer look at nonmodifiable factors and their potential use in treatment. Pancreas. 2019;48(2):242-9. https://doi.org/1 0.1097/MPA.0000000000001238.

15. Abdel-Rahman O. Impact of $\mathrm{NCl}$ socioeconomic index on the outcomes of nonmetastatic breast Cancer patients: analysis of SEER census tract-level socioeconomic database. Clin Breast Cancer. 2019;19(6):e717-e22. https:// doi.org/10.1016/j.clbc.2019.06.013.

16. Gabriel E, Attwood K, Al-Sukhni E, Erwin D, Boland P, Nurkin S. Age-related rates of colorectal cancer and the factors associated with overall survival. J Gastrointest Oncol. 2018;9(1):96-110. https://doi.org/10.21037/jgo.2017.11.13.

17. Silber JH, Rosenbaum PR, Ross RN, Reiter JG, Niknam BA, Hill AS, et al. Disparities in breast Cancer survival by socioeconomic status despite Medicare and Medicaid insurance. Milbank Q. 2018;96(4):706-54. https://doi. org/10.1111/1468-0009.12355.

18. Moore JX, Royston KJ, Langston ME, Griffin R, Hidalgo B, Wang HE, et al. Mapping hot spots of breast cancer mortality in the United States: place matters for blacks and Hispanics. Cancer Causes Control. 2018;29(8):737-50. https://doi.org/10.1007/s10552-018-1051-y. 
19. Shi R, Taylor H, McLarty J, Liu L, Mills G, Burton G. Effects of payer status on breast cancer survival: a retrospective study. BMC Cancer. 2015;15(1):211. https://doi.org/10.1186/s12885-015-1228-7.

20. Goebel M, Singal AG, Nodora J, Castaneda SF, Martinez E, Doubeni C, et al. How can we boost colorectal and hepatocellular cancer screening among underserved populations? Curr Gastroenterol Rep. 2015;17(6):22. https://doi. org/10.1007/s11894-015-0445-1.

21. Jemal A, Siegel RL, Ma J, Islami F, DeSantis C, Goding Sauer A, et al. Inequalities in premature death from colorectal cancer by state. J Clin Oncol. 2015;33(8):829-35. https://doi.org/10.1200/JCO.2014.58.7519.

22. Hunt BR, Silva A, Lock D, Hurlbert M. Predictors of breast cancer mortality among white and black women in large United States cities: an ecologic study. Cancer Causes Control. 2019;30(2):149-64. https://doi.org/10.1007/s1 0552-018-1125-X

23. Shariff-Marco S, Yang J, John EM, Kurian AW, Cheng I, Leung R, et al. Intersection of race/ethnicity and socioeconomic status in mortality after breast Cancer. J Community Health. 2015;40(6):1287-99. https://doi.org/10.1 007/s10900-015-0052-y.

24. Sun M, Cole AP, Lipsitz SL, Trinh QD. Trends in breast, colorectal, and cervical cancer incidence following the affordable care act: implications for cancer screening. JAMA Oncol. 2018;4(1):128-9. https://doi.org/10.1001/jama oncol.2017.3861.

25. Gan T, Sinner HF, Walling SC, Chen Q, Huang B, Tucker TC, et al. Impact of the affordable care act on colorectal Cancer screening, incidence, and survival in Kentucky. J Am Coll Surg. 2019;228(4):342-53 e1. https://doi.org/1 0.1016/j.jamcollsurg.2018.12.035.

26. Hendryx $M$, Luo J. Increased Cancer screening for low-income adults under the affordable care act Medicaid expansion. Med Care. 2018;56(11):944-9. https://doi.org/10.1097/MLR.0000000000000984.

27. Bureau, US Census. "Cps Historical Time Series Tables." The United States Census Bureau, 20 Apr. 2021, www.census.gov/data/tables/time-series/ demo/educational-attainment/cps-historical-time-series.html.

28. US. National Center for Health Statistics. Division of Vital Statistics. National Vital Statistic System. Data Acquisition and Evaluation Branch. Instruction manuals. Part 4: Classification and Coding Instructions for Death Records, 1999-2001. (2001, pp 1-54). https://www.cdc.gov/nchs/nvss/instruction-ma nuals.htm.

29. Nolte $\mathrm{E}, \mathrm{McKee}$ M. Measuring the health of nations: analysis of mortality amenable to health care. Br Med J. 2003;327(7424):1129-32. https://doi. org/10.1136/bmj.327.7424.1129.

30. Franks P, Clancy CM, Gold MR. Health insurance and mortality: evidence from a National Cohort. JAMA. 1993;270(6):737-41. https://doi.org/10.1001/ja ma.1993.03510060083037.

31. Galea S, Tracy M, Hoggatt KJ, Dimaggio C, Karpati A. Estimated deaths attributable to social factors in the United States. Am J Public Health. 2011; 101(8):1456-65. https://doi.org/10.2105/AJPH.2010.300086.

32. Rogers RG, Hummer RA, Everett BG. Educational differentials in US adult mortality: an examination of mediating factors. Soc Sci Res. 2013;42(2):46581. https://doi.org/10.1016/j.ssresearch.2012.09.003.

33. Rogers RG, Everett BG, Zajacova A, Hummer RA. Educational degrees and adult mortality risk in the United States. Biodemography Soc Biol. 2010; 56(1):80-99. https://doi.org/10.1080/19485561003727372.

34. Montez JK, Hummer RA, Hayward MD. Educational attainment and adult mortality in the United States: a systematic analysis of functional form. Demography. 2012;49(1):315-36. https://doi.org/10.1007/s13524011-0082-8.

35. Montez JK, Zajacova A, Hayward MD, Woolf SH, Chapman D, Beckfield J. Educational disparities in adult mortality across U.S. states: how do they differ, and have they changed since the mid-1980s? Demography. 2019;56(2):621-44. https://doi.org/10.1007/s13524-018-0750-z.

36. Nolte $\mathrm{E}, \mathrm{McKee} \mathrm{CM}$. Measuring the health of nations: updating an earlier analysis. Health Aff. 2008;27(1):58-71. https://doi.org/10.1377/hlthaff.27.1.58.

37. National Cancer Institute. Joinpoint regression program, version 4.8.0.1. 2020. https://surveillance.cancer.gov/joinpoint/.

38. Kim HJ, Fay MP, Feuer EJ, Midthune DN. Permutation tests for joinpoint regression with applications to cancer rates. Stat Med. 2000;19(3):335-51. https://doi.org/10.1002/(SICI)1097-0258(20000215)19:3<335::AID-SIM336>3.0. $\mathrm{CO} ; 2-\mathrm{Z}$

39. Clegg LX, Hankey BF, Tiwari R, Feuer EJ, Edwards BK. Estimating average annual per cent change in trend analysis. Stat Med. 2009;28(29):3670-82 https://doi.org/10.1002/sim.3733.
40. Roy B, Kiefe Cl, Jacobs DR, Goff DC, Lloyd-Jones D, Shikany JM, et al. Education, race/ethnicity, and causes of premature mortality among middle-aged adults in 4 US urban communities: results from CARDIA, 19852017. Am J Public Health. 2020;110(4):530-6. https://doi.org/10.2105/AJPH.2 019.305506

41. Rostron BL, Boies $J$, Arias E. Education reporting and classification on death certificates in the United States. Vital Health Stat. 2010;2(151):1-21.

42. Sorlie PD, Johnson NJ. Validity of education information on the death certificate. Epidemiology. 1996;7(4):437-9.

43. Sung $H$, Siegel RL, Rosenberg PS, Jemal A. Emerging cancer trends among young adults in the USA: analysis of a population-based cancer registry. Lancet Public Health. 2019;4(3):e137-e47. https://doi.org/10.1016/S2468-2 667(18)30267-6.

44. Chetty R, Stepner M, Abraham S, Lin S, Scuderi B, Turner N, et al. The association between income and life expectancy in the United States, 2001 2014. JAMA. 2016;315(16):1750-66. https://doi.org/10.1001/jama.2016.4226.

45. Cutler D, Lleras-Muney A. (2014) Education and Health. In Culver AJ (Ed). Encyclopedia Health Economics. Elsevier (1st ed, pp 232-45) ISBN: 9780123756787

46. Meara ER, Richards S, Cutler DM. The gap gets bigger: changes in mortality and life expectancy, by education, 1981-2000. Health Aff. 2008;27(2):350-60. https://doi.org/10.1377/hlthaff.27.2.350.

47. Singh GK, Jemal A. Socioeconomic and racial/ethnic disparities in Cancer mortality, incidence, and survival in the United States, 1950-2014: over six decades of changing patterns and widening inequalities. J Environ Public Health. 2017;2017:2819372

48. Dean LT, Gehlert S, Neuhouser ML, Oh A, Zanetti K, Goodman M, et al. Social factors matter in cancer risk and survivorship. Cancer Causes Control. 2018;29(7):611-8. https://doi.org/10.1007/s10552-018-1043-y.

49. American Cancer Society Facts \& Figures for African Americans: 2019-2021. Atlanta: American Cancer Society; 2019. https://www.cancer.org/content/da $\mathrm{m} /$ cancer-org/research/cancer-facts-and-statistics/cancer-facts-and-figuresfor-african-americans/cancer-facts-and-figures-for-african-americans-2019-2 021.pdf.

50. Yedjou CG, Tchounwou PB, Payton M, Miele L, Fonseca DD, Lowe L, et al. Assessing the racial and ethnic disparities in breast cancer mortality in the United States. Int J Environ Res Public Health. 2017;14(5):1-14. https://doi. org/10.3390/ijerph14050486.

51. Sarma EA, Rendle KA, Kobrin SC. Cancer symptom awareness in the US: Sociodemographic differences in a population-based survey of adults. Prev Med. 2020;132:106005. https://doi.org/10.1016/j.ypmed.2020.106005.

52. Landrine H, Corral I, Lee JGL, Efird JT, Hall MB, Bess JJ. Residential segregation and racial Cancer disparities: a systematic review. J Racial Ethn Health Disparities. 2017;4(6):1195-205. https://doi.org/10.1007/s40615-0160326-9.

53. Smaradottir BF, Fensli RW. User experiences and satisfaction with an electronic health record system (Conference paper). Advances in Intelligent Systems and Computing. 2020;972:73-80. https://doi.org/10.1007/978-3-03 0-19135-1_8.

54. Wang M, Chi G, Bodovski Y, Holder SL, Lengerich EJ, Wasserman E, et al. Temporal and spatial trends and determinants of aggressive prostate cancer among black and white men with prostate cancer. Cancer Causes Control. 2020;31(1):63-71. https://doi.org/10.1007/s10552-019-01249-0.

55. Percy-Laurry A. Socioeconomic status and the aggressiveness of prostate cancer among black males. Cancer Res. 2015;75(15):277. https://doi.org/1 0.1158/1538-7445.AM2015-LB-277.

56. Bhupathiraju SN, Grodstein F, Stampfer MJ, Willett WC, Hu FB, Manson JE. Exogenous hormone use: Oral contraceptives, postmenopausal hormone therapy, and health outcomes in the Nurses' health study. Am J Public Health. 2016;106(9):1631-7. https://doi.org/10.2105/AJPH.2016.303349.

57. Million Woman Study Collaboration. Breast cancer and hormone-replacement therapy in the million women study. Lancet. 2003;362(9382):419-27.

58. Howlader N, Noone AM, Krapcho M, Miller D, Brest A, Yu M, Ruhl J, Tatalovich Z, Mariotto A, Lewis DR, Chen HS, Feuer EJ, Cronin KA (eds). SEER Cancer Statistics Review, 1975-2017, National Cancer Institute. Bethesda, MD, https://seer.cancer.gov/csr/1975_2017/, based on November 2019 SEER data submission, posted to the SEER web site, April 2020.

59. Kong $X$, Liu Z, Cheng $R$, Sun L, Huang $S$, Fang $Y$, et al. Variation in breast Cancer subtype incidence and distribution by race/ethnicity in the United States from 2010 to 2015. JAMA Netw Open. 2020;3(10):e2020303. https:// doi.org/10.1001/jamanetworkopen.2020.20303. 
60. Richardson LC, Henley SJ, Miller JW, Massetti G, Thomas CC. Patterns and trends in age-specific black-white differences in breast Cancer incidence and mortality - United States, 1999-2014. MMWR Morb Mortal Wkly Rep. 2016;65(40):1093-8. https://doi.org/10.15585/mmwr.mm6540a1.

61. Smigal C, Jemal A, Ward E, Cokkinides V, Smith R, Howe HL, et al. Trends in breast cancer by race and ethnicity: update 2006. Ca-A Cancer J Clin. 2006; 56(3):168-83. https://doi.org/10.3322/canjclin.56.3.168.

62. DeSantis CE, Fedewa SA, Goding Sauer A, Kramer JL, Smith RA, Jemal A. Breast cancer statistics, 2015: convergence of incidence rates between black and white women. CA Cancer J Clin. 2016;66(1):31-42. https://doi.org/1 $0.3322 /$ caac. 21320

63. Fedewa SA, Edge SB, Stewart AK, Halpern MT, Marlow NM, Ward EM. Race and ethnicity are associated with delays in breast cancer treatment (20032006). J Health Care Poor Underserved. 2011;22(1):128-41. https://doi.org/1 0.1353/hpu.2011.0006

64. Allemani C, Weir HK, Carreira H, Harewood R, Spika D, Wang XS, et al. Global surveillance of cancer survival 1995-2009: analysis of individual data for 25 676887 patients from 279 population-based registries in 67 countries (CONCORD-2). Lancet. 2015;385(9972):977-1010. https://doi.org/10.1016/ S0140-6736(14)62038-9.

65. Wheeler SB, Reeder-Hayes KE, Carey LA. Disparities in breast cancer treatment and outcomes: biological, social, and health system determinants and opportunities for research. Oncologist. 2013;18(9):986-93. https://doi. org/10.1634/theoncologist.2013-0243.

66. Chlebowski RT, Aragaki AK, Anderson GL, Prentice RL. Forty-year trends in menopausal hormone therapy use and breast cancer incidence among postmenopausal black and white women. Cancer. 2020;126(13):2956-64. https://doi.org/10.1002/cncr.32846.

67. Kahlenborn C, Modugno F, Potter DM, Severs WB. Oral contraceptive use as a risk factor for premenopausal breast cancer: a meta-analysis. Mayo Clin Proc. 2006;81(10):1290-302. https://doi.org/10.4065/81.10.1290.

68. Charlton BM, Rich-Edwards JW, Colditz GA, Missmer SA, Rosner BA, Hankinson SE, et al. Oral contraceptive use and mortality after 36 years of follow-up in the Nurses' Health Study: prospective cohort study. BMJ. 2014; 349:96356.

69. Singh GK, Daus GP, Allender M, Ramey CT, Martin EK, Perry C, et al. Social determinants of health in the United States: addressing major health inequality trends for the nation, 1935-2016. Int J of MCH AIDS. 2017;6(2): 139-64. https://doi.org/10.21106/ijma.236.

70. Bandera EV, Maskarinec G, Romieu I, John EM. Racial and ethnic disparities in the impact of obesity on breast cancer risk and survival: a global perspective. Adv Nutr. 2015;6(6):803-19.

71. Cote ML, Alhajj T, Ruterbusch JJ, Bernstein L, Brinton LA, Blot WJ, et al. Risk factors for endometrial cancer in black and white women: a pooled analysis from the epidemiology of endometrial Cancer consortium (E2C2). Cancer Causes Control. 2015;26(2):287-96. https://doi.org/10.1007/s1 0552-014-0510-3.

72. Global Burden of Disease Cancer Collaboration. Global, Regional, and National Cancer Incidence, Mortality, Years of Life Lost, Years Lived with Disability, and Disability-Adjusted Life-Years for 29 Cancer Groups, 1990 to2016: A Systematic Analysis for the Global Burden of Disease Study. JAMAOncol. 2018:4(11):155368. https://doi.org/10.1001/jamaoncol.2018.2706.

73. Borondy Kitts AK. The patient perspective on lung cancer screening and health disparities. J Am Coll Radiol. 2019;16(4 Pt B):601-6.

\section{Publisher's Note}

Springer Nature remains neutral with regard to jurisdictional claims in published maps and institutional affiliations.

Ready to submit your research? Choose BMC and benefit from:
- fast, convenient online submission
- thorough peer review by experienced researchers in your field
- rapid publication on acceptance
- support for research data, including large and complex data types
- gold Open Access which fosters wider collaboration and increased citations
- maximum visibility for your research: over 100M website views per year
At BMC, research is always in progress.
Learn more biomedcentral.com/submissions

